\title{
Remarkable Effect of PEG-1000-based Dicationic Ionic Liquid for $N$-hydroxyphthalimide-catalyzed Aerobic Selective Oxidation of Alkylaromatics
}

\author{
Tingting Lu, Ming Lu, * Wang Yu, and Zhongjie Liu
}

School of Chemical Engineering, Nanjing University of Science and Technology, Nanjing 210094, P. R. China

\begin{abstract}
PEG 1000-based functional dicationic acidic ionic liquid ( $\left.\mathrm{PEG}_{1000}-\mathrm{DAIL}\right)$ was used for the first time as the reaction solvent for the $\mathrm{N}$-Hydroxyphthalimide (NHPI)-cobalt acetate $\left(\mathrm{Co}(\mathrm{OAc})_{2}\right)$ catalyzed aerobic oxidations of alkylaromatics to the corresponding acids. It enhanced the efficient catalytic ability of NHPI: $99.9 \%$ conversion of toluene with $99.5 \%$ selectivity for benzoic acid could be obtained at $80^{\circ} \mathrm{C}$ in $10 \mathrm{~h}$ and ethylbenzene was selectively oxidized to benzoic acid. Several alkylaromatics were efficiently oxidized to their corresponding acids under mild conditions. For substituted toluene, the conversions of substrates and the selectivity of products was affected by the position and kind of substituted groups, respectively. Both the catalyst and $\mathrm{PEG}_{1000}-\mathrm{DAIL}$ could be reused at least eight times without significantly decreasing the catalytic activity.(doi: 10.5562/cca2051)
\end{abstract}

Keywords: aerobic oxidation, alkylaromatics, NHPI, $\mathrm{PEG}_{1000}-\mathrm{DAIL}$, ionic liquid

\section{INTRODUCTION}

The catalytic oxidation of alkylaromatics with molecular oxygen is of major industrial importance, and improving its efficiency and selectivity for the valueadded products remains a challenge. ${ }^{1}$ The success of these oxygenations always depends largely on the development of catalysts to promote productivity, the rate of reaction, as well as the selectivity of products. ${ }^{2}$ In recent years, due to its highly catalytic efficiencies even under mild conditions for the aerobic oxidation of various organic compounds in the presence of some metallic compounds or non-metallic compounds, $\mathrm{N}$ hydroxyphthalimide (NHPI) is attracting continuous attention. ${ }^{3-6}$ However, the progress of using NHPI suffers from difficulties encountered in the reuse of catalyst for new reactions ${ }^{7}$ and employed corrosive acetic acid. $^{8}$

Ionic liquids (ILs) are a special class of molten salts composed of organic cations and inorganic or organic anions. They have many excellent advantages such as negligible volatility, excellent thermal stability, remarkable solubility, and a variety of available structures. $^{9}$ It should be the most appropriate solvent to replace acetic acid for the NHPI catalyzed aerobic oxidation of hydrocarbons and a few examples have been reported. In 2005, Wang reported the first exam- ple of an aerobic oxidation with NHPI catalysts in ionic liquid. ${ }^{10}$ Liu et al. reported oxidation of alkylbenzenes (such as ethylbenzene and $n$-propylbenzene) using NHPI with $\mathrm{Co}(\mathrm{II}), \mathrm{Mn}(\mathrm{II})$ or $\mathrm{Ni}(\mathrm{II})$ in various ILs (including $[\mathrm{Hex}-\mathrm{mim}] \mathrm{BF}_{4},\left[\mathrm{Bmim} \mathrm{PF}_{6},[\mathrm{Bmim}] \mathrm{BF}_{4}\right.$ and [Omim] $\mathrm{BF}_{4}$ ) with molecular oxygen. ${ }^{11}$ Later, Yavari reported a mild oxidation reaction of xylenes to phthalic acids with $N$-hydroxyphthalimide and $\mathrm{HNO}_{3}$ in bmim[OMS]. ${ }^{12}$ However, these ILs are inevitably associated with one or more disadvantages, such as low recovery ratio, high cost or difficulty of synthesis and the low selectivity. To improve catalyst recovery and the selectivity, some novel ionic liquid like PEG based ionic liquid have been considered due to their some advantages, such as high conversions and selectivity, stability at high temperatures, and reusability in the reaction. ${ }^{13}$

We now report an efficient and convenient procedure for the oxidation of aromatic hydrocarbons catalyzed by NHPI in PEG 1000-based dicationic ionic liquid $\left(\mathrm{PEG}_{1000}-\mathrm{DAIL}\right)^{14}$ (Scheme 1). Oxidation was surveyed using a host of aromatic substrates with similar reactivity and high selectivity of acid, wherein both the catalyst and $\mathrm{PEG}_{1000}$-DAIL can be successfully recovered and reused. The easily recovered ionic liquid opened up the possibility of a more economic process.

\footnotetext{
* Author to whom correspondence should be addressed. (E-mail: tt252525@gmail.com)
} 


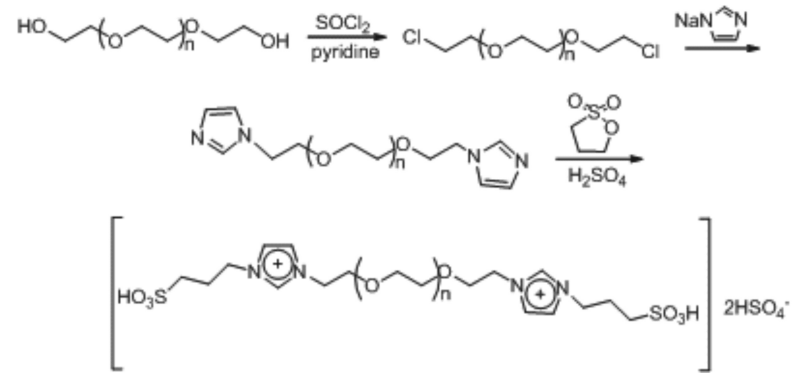

Scheme 1. The preparation of the PEG-DAIL.

\section{EXPERIMENTAL SECTION}

All starting materials were purchased from commercial sources and used without further treatment. ${ }^{1} \mathrm{H}$ NMR $(500 \mathrm{MHz})$ and ${ }^{13} \mathrm{C}$ NMR $(125 \mathrm{MHz})$ were recorded on a Bruker 500 spectrometer using $\mathrm{D}_{2} \mathrm{O}$ as the solvent with tetramethylsilane (TMS) as an internal standard. IR spectra were recorded on a Bruker Vector 22 infrared spectrometer, as $\mathrm{KBr}$ pellets with absorption in $\mathrm{cm}^{-1}$. High performance liquid chromatography (HPLC) experiments were performed on a liquid chromatograph (Dionex Softron GmbH, America), consisting of a pump (P680) and UV/Vis light detector system (170U). The experiments were performed on a Diacovery C18 column; ø $4.6 \times 250 \mathrm{~mm}$. The conversions of the substrates and the selectivities of products were estimated from the peak areas based on the internal standard technique. The products were determined in some cases by comparison of their HPLC with those of authentic samples.

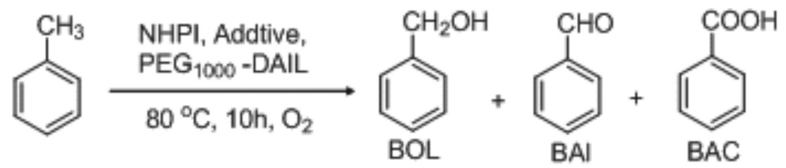

Scheme 2. Aerobic oxidation of Toluene by NHPI in $\mathrm{PEG}_{1000}-\mathrm{DAIL}$.

The $\mathrm{PEG}_{1000}-\mathrm{DAIL}$ was prepared by the procedure given in the literature (Scheme 1). ${ }^{14}$

The substrate $(0.05 \mathrm{~mol}), \mathrm{PEG}_{1000}-\mathrm{DAIL}(2.8 \times$ $\left.10^{-4} \mathrm{~mol}\right)$, NHPI $\left(5 \times 10^{-3} \mathrm{~mol}, 10 \mathrm{~mol} \%\right)$, and $\mathrm{Co}(\mathrm{OAc})_{2}$ $\left(2.5 \times 10^{-4} \mathrm{~mol}, 0.5 \mathrm{~mol} \%\right)$ were placed in a three-necked flasks. The flask was purged with a stream of $\mathrm{O}_{2}$ at a flow rate of $20 \mathrm{~mL} \mathrm{~min}^{-1}$. The reaction mixture was stirred at a specific temperature for a specific time (Table 2), and the reaction progress was monitored by HPLC. After completion of the reaction, the mixture was cooled to room temperature and extracted with $10 \mathrm{ml}$ ether for three times. After concentration of the ether solution, the products were taken for HPLC measurement and the $\mathrm{PEG}_{1000}$ DAIL was reused without any treatment.

\section{RESULTS AND DISCUSSION}

For the initial study, toluene was selected as the model substrates (Scheme 2) to optimize the reaction conditions (Table 1).

It is indicated that the oxidation of toluene with $\mathrm{O}_{2}$ (1 atm) catalyzed by NHPI (10 mol \%) combined with

Table 1. Oxidation of toluene with $\mathrm{O}_{2}$ by NHPI under various conditions ${ }^{(\mathrm{a})}$

\begin{tabular}{|c|c|c|c|c|c|c|c|}
\hline \multirow[t]{2}{*}{ Run } & \multirow{2}{*}{$\begin{array}{c}\text { NHPI } \\
(\mathrm{mol} \mathrm{\% )}\end{array}$} & \multirow[t]{2}{*}{ Additive (mol \%) } & \multirow[t]{2}{*}{ Solvent $^{(\mathrm{b})}$} & \multirow[t]{2}{*}{ Conversion $/ \%$} & \multicolumn{3}{|c|}{ Products selectivity / \% } \\
\hline & & & & & $\mathrm{BOL}$ & $\mathrm{BAl}$ & $\mathrm{BAC}$ \\
\hline 1 & 10 & $\mathrm{Co}(\mathrm{OAc})_{2}(0.5)$ & $\mathrm{PEG}_{1000}-\mathrm{DAIL}$ & 99.9 & 0.3 & n.d. ${ }^{(c)}$ & 99.5 \\
\hline 2 & 5 & $\mathrm{Co}(\mathrm{OAc})_{2}(0.5)$ & $\mathrm{PEG}_{1000}-\mathrm{DAIL}$ & 58.9 & 7.2 & 1.7 & 91.1 \\
\hline 3 & 10 & & $\mathrm{PEG}_{1000}-\mathrm{DAIL}$ & 48.7 & 1.9 & 20.0 & 78.1 \\
\hline 4 & 0 & & $\mathrm{PEG}_{1000}-\mathrm{DAIL}$ & n.d. & n.d. & n.d. & n.d. \\
\hline 5 & 10 & $\mathrm{Co}(\mathrm{acac})_{2}(0.5)$ & $\mathrm{PEG}_{1000}-\mathrm{DAIL}$ & 90.1 & 26.0 & n.d. & 74.0 \\
\hline 6 & 10 & $\mathrm{Mn}(\mathrm{OAc})_{2}(0.5)$ & $\mathrm{PEG}_{1000}-\mathrm{DAIL}$ & 92.0 & 58.3 & n.d. & 41.7 \\
\hline 7 & 10 & $\begin{array}{l}\mathrm{Co}(\mathrm{OAc})_{2}(0.5)+ \\
\mathrm{Mn}(\mathrm{OAc})_{2}(0.05)\end{array}$ & $\mathrm{PEG}_{1000}-\mathrm{DAIL}$ & 100 & 2.3 & n.d. & 97.7 \\
\hline 8 & 10 & Dimethylglyoxime (10) & $\mathrm{PEG}_{1000}-\mathrm{DAIL}$ & 89.8 & 94.6 & n.d. & 5.00 \\
\hline 9 & 10 & anthraquinone (1.25) & $\mathrm{PEG}_{1000}-\mathrm{DAIL}$ & 87.9 & n.d. & 29.9 & 70.1 \\
\hline 10 & 10 & ABIN (3) & $\mathrm{PEG}_{1000}-\mathrm{DAIL}$ & 37.2 & 0.6 & 30.0 & 69.4 \\
\hline $11^{(\mathrm{d})}$ & 10 & nitric acid (5) & $\mathrm{PEG}_{1000}-\mathrm{DAIL}$ & 14.0 & 69.3 & 30.7 & n.d. \\
\hline $12^{(\mathrm{e})}$ & 10 & $\mathrm{Co}(\mathrm{OAc})_{2}(0.5)$ & HOAc & 84.2 & n.d. & 2.7 & 96.1 \\
\hline 13 & 10 & $\mathrm{Co}(\mathrm{OAc})_{2}(0.5)$ & $\mathrm{CH}_{3} \mathrm{CN}$ & 52.1 & n.d. & 45.0 & 52.9 \\
\hline 14 & 10 & $\mathrm{Co}(\mathrm{OAc})_{2}(0.5)$ & $\mathrm{CH}_{2} \mathrm{Cl}_{2}$ & 61.4 & 3.6 & 41.2 & 55.0 \\
\hline 15 & 10 & $\mathrm{Co}(\mathrm{OAc})_{2}(0.5)$ & {$[$ Hex-mim $] \mathrm{BF}_{4}$} & 31.2 & 12.5 & 47.2 & 39.9 \\
\hline 16 & 10 & $\mathrm{Co}(\mathrm{OAc})_{2}(0.5)$ & {$[\mathrm{Bmim}] \mathrm{PF}_{6}$} & 16.7 & n.d. & 8.8 & 90.1 \\
\hline 17 & 10 & $\mathrm{Co}(\mathrm{OAc})_{2}(0.5)$ & $\mathrm{PEG}_{1000}-\mathrm{DIL}$ & 98.5 & 7.1 & 86.7 & 6.2 \\
\hline
\end{tabular}

(a) Toluene $(0.05 \mathrm{~mol})$ was allowed to react with $\mathrm{O}_{2}(1 \mathrm{~atm})$ in the presence of NHPI and additive in solvent at $80{ }^{\circ} \mathrm{C}$ for $10 \mathrm{~h}$.

(b) $\mathrm{PEG}_{1000}$-DAIL was $2.8 \times 10^{-4} \mathrm{~mol}$ and other solvent was $10 \mathrm{ml}$.

(c) Not detected.

(d) The concentration of nitric acid was $67 \%$.

(e) The reaction temperature is $25^{\circ} \mathrm{C}$ and the time is $20 \mathrm{~h}$. 
Table 2. Aerobic Oxidation of Various Substrates Catalyzed by NHPI in $\mathrm{PEG}_{1000}-\mathrm{DAIL}^{(\mathrm{a})}$

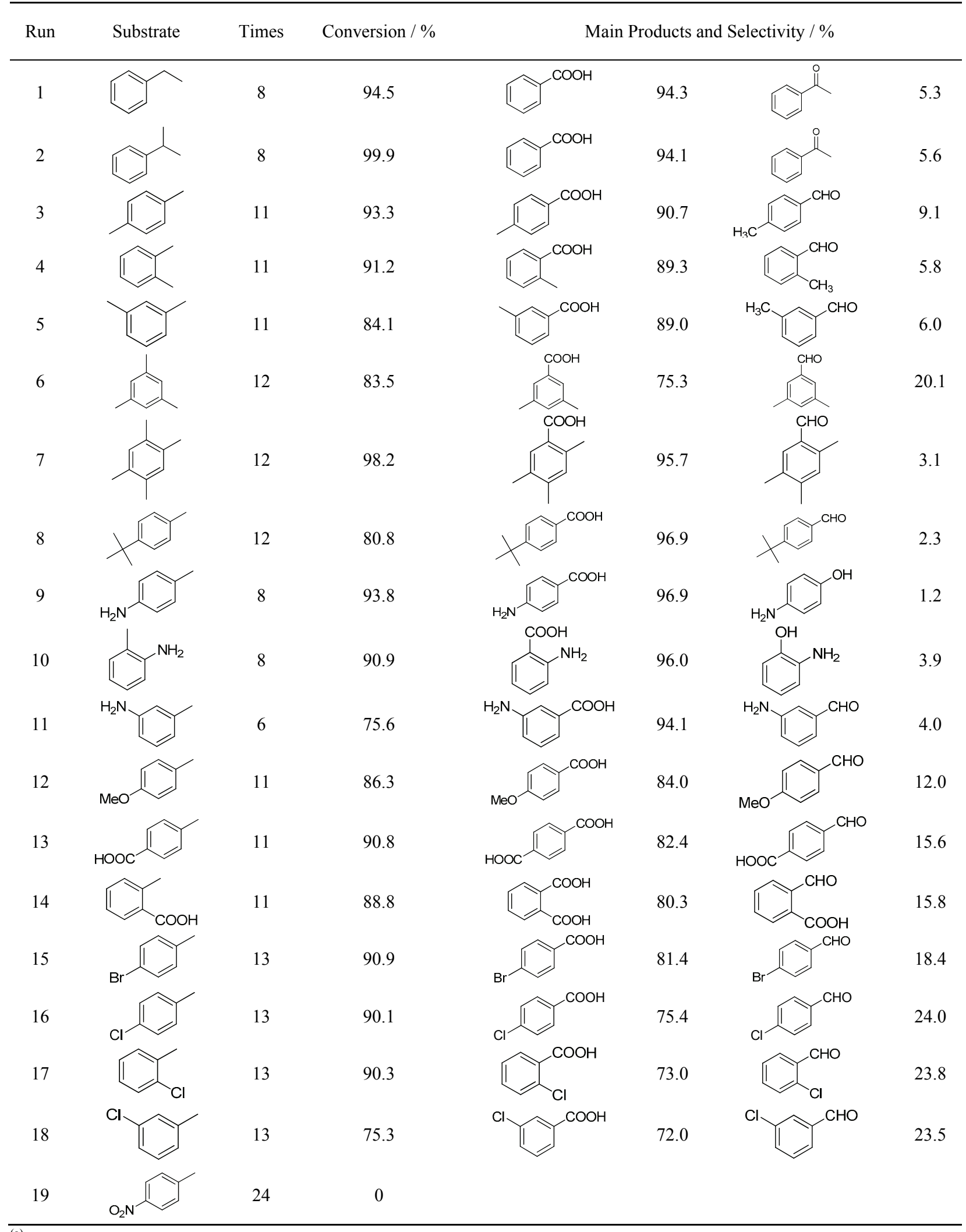

(a) Reaction conditions: $0.05 \mathrm{~mol}$ substrate, $10 \mathrm{~mol} \%$ NHPI, $0.5 \mathrm{~mol} \% \mathrm{Co}(\mathrm{OAc}) 2,2.8 \times 10-4 \mathrm{~mol} \mathrm{PEG}_{1000}-\mathrm{DAIL}, 80{ }^{\circ} \mathrm{C}$, $1 \mathrm{~atm} \mathrm{O}_{2}$. Coversions and selectivities were determined by HPLC. 


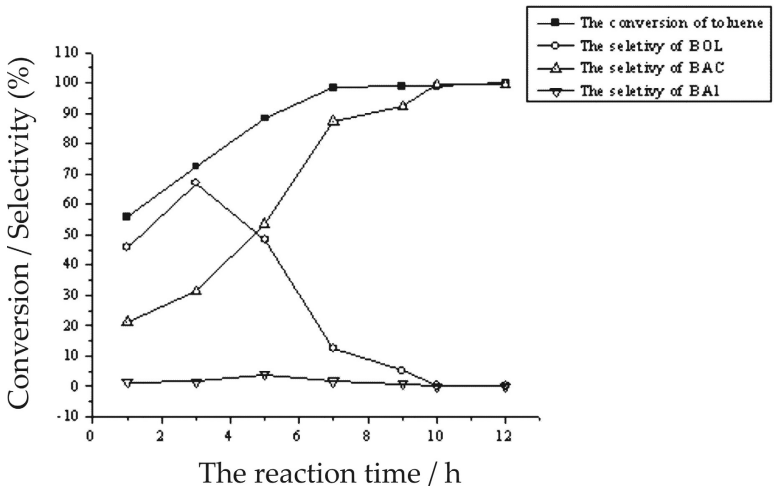

Figure 1. Time-dependence curve for the aerobic oxidation of toluene ${ }^{(a)}$

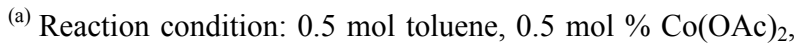
$10 \mathrm{~mol} \mathrm{\%} \mathrm{NHPI,} 2.8 \times 10^{-4} \mathrm{~mol} \mathrm{PEG}_{1000}-\mathrm{DAIL}, 80^{\circ} \mathrm{C}$.

$\mathrm{Co}(\mathrm{OAc})_{2}(0.5 \mathrm{~mol} \%)$ gave benzyl alcohol (BOL), benzoic acid (BAC) in $0.3 \%$ and $99.5 \%$ selectivity, respectively, at $99.9 \%$ conversion (Table 1, Run 1). This shows that toluene is completely oxidized with $\mathrm{O}_{2}$ by NHPI to give selectively BAC. When the amount of NHPI was halved, the conversion was sharply decreased and a considerable amount of BOL and benzaldehyde (BAl) was formed (Run 2). Removing $\mathrm{Co}(\mathrm{OAc})_{2}$ from the oxidation system resulted in lower conversion with the concomitant gradual increase of $\mathrm{BAl}$ and the decrease of BAC in the selectivities (Run 3). However, no oxidation was induced when $\mathrm{PEG}_{1000}$-DAIL was used alone (Run 4). Substitution of $\mathrm{Co}(\mathrm{OAc})_{2}$ by $\mathrm{Co}(\mathrm{acac})_{2}$ (Ref. 15) or $\mathrm{MnO}_{2}$ (Ref. 3) led to a slightly lower conversion with comparable selectivity toward the formation of BAC (Run 5 and 6). When both $\mathrm{Co}(\mathrm{OAc})_{2}$ and $\mathrm{Mn}(\mathrm{OAc})_{2}$ were used, ${ }^{15}$ the conversion increased but the selectivity for BAC was slightly decreased (Run 7).

In the previous papers, it was shown that some non-metallic compounds such as azobisisobutyronitrile $(\mathrm{ABIN})^{16}$ or $\mathrm{HNO}_{3}{ }^{12}$ also can abstract the hydrogen atom from the hydroxyimide moiety of the NHPI to generate phthalimide $N$-oxyl (PINO) which abstracts the hydrogen atom from the methyl moiety of toluene. Thus, the oxidation of toluene was examined by nonmetallic radical initiator. Unsatisfactorily, when dimethylglyoxime $^{6}$ and anthraquinone ${ }^{17,18}$ were employed, the conversion with selectivity evidently declined (Run 8 and 9). And in the presence of the ABIN (Run 10), the reaction proceeded in much low conversion to result in lots of undesired products (BAl). To our disappointment, the conversion reached only $14.0 \%$ and no benzoic acid appeared when $\mathrm{HNO}_{3}$ was used instead (Run 11).

Subsequently, several solvents were evaluated. In contrast to the traditional $\mathrm{NHPI} / \mathrm{Co}(\mathrm{OAc})_{2}$ catalyzed aerobic oxidation of toluene where acetic $\mathrm{acid}^{8}$ was the

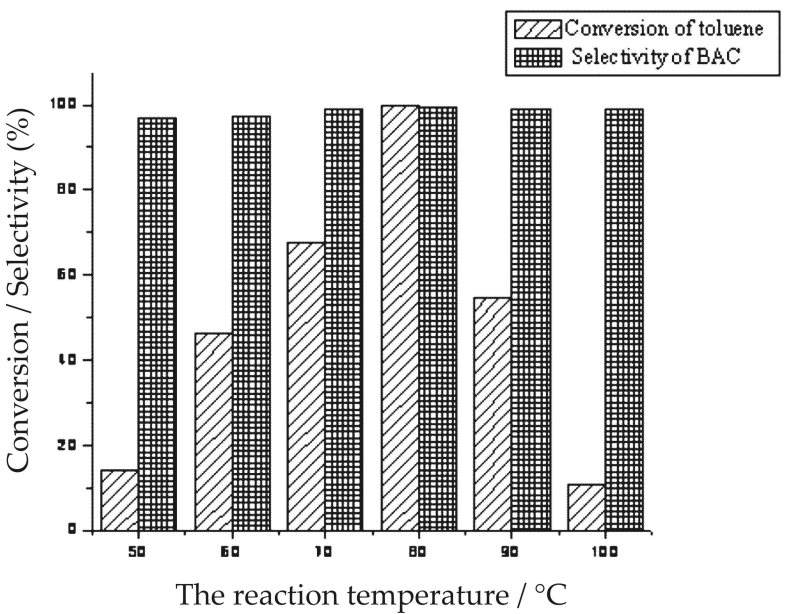

Figure 2. Temperature-dependence curve for the aerobic oxidation of toluene $\mathrm{e}^{(\mathrm{a})}$

(a) Reaction condition: $0.5 \mathrm{~mol}$ toluene, $0.5 \mathrm{~mol} \% \mathrm{Co}(\mathrm{OAc})_{2}$, 10 mol\% NHPI, $2.8 \times 10^{-4} \mathrm{~mol} \mathrm{PEG}_{1000}-\mathrm{DAIL}, 10 \mathrm{~h}$.

most appropriate solvent (Run 12), the employment of $\mathrm{PEG}_{1000}$-DAIL led to a higher conversion and selectivity of BAC and lower selectivity of side product BAl (Run 1). It was indicated $\mathrm{PEG}_{1000}$-DAIL increased the efficient catalytic ability of NHPI. In presence of acetonitrile and dichloromethane, the conversions and selectivities of BAC were relatively low (Run 13 and 14). Traditional ionic liquids $[\mathrm{Hex}-\mathrm{mim}] \mathrm{BF}_{4}$ and [Bmim $] \mathrm{PF}_{6}{ }^{11}$ were also tested, however, poor conversions were observed (Run 15 and 16). The reaction in $\mathrm{PEG}_{1000}$-DIL (PEG 1000-based dicationic ionic liquid) resulted in slightly lower conversion and selectivity due to its lack of acidity (Run 17).

In order to obtain information on the reaction course of the present reaction, the oxidation of toluene with $\mathrm{O}_{2}(1 \mathrm{~atm})$ under the influence of NHPI and $\mathrm{Co}(\mathrm{OAc})_{2}$ was monitored as a function of time and temperature (Figure 1 and 2).

The changes of product distribution of toluene oxidation with time are shown in Figure 1. As illustrated, the conversion of toluene increased with prolonging the reaction time and the selectivity of BOL increased rapidly in the initial $2.0 \mathrm{~h}$. In the same period of time, the selectivity of BAC increased slowly. With the further increase of time, the selectivity of BAC continuously increased, but the selectivity of BOL decreased due to the continuous oxidation of BOL to BAC. However, after 10 $\mathrm{h}$ the conversion was changed slowly and became stagnated near $99.9 \%$. As a result, in a $10 \mathrm{~h}$ reaction course, $99.9 \%$ toluene was oxidized with $99.5 \%$ selectivity of BAC. The change of the selectivity of BAl was similar to BOL except the concentrate was always low.

The effect of temperature on oxidation of toluene was investigated and shown in Figure 2. Since the solu- 
bility of toluene in $\mathrm{PEG}_{1000}$-DAIL increase with the raise of the temperature, the conversion first increased as the reaction temperature rose but then gradually decreased when the temperature was elevated beyond $80{ }^{\circ} \mathrm{C}$, which was probably because lots of toluene was gasified at higher reaction temperature. On the contrary, the selectivity of BAC was almost unchanged and almost no side products such as BAl were found.

With optimized conditions in hand, we then turned our attention to the scope of the reaction, and the results are shown in Table 2. First, ethylbenzene and cumene were oxidized under the optimized reaction conditions, respectively (Run 1 and 2). To our surprise the main product was benzoic acid but not acetophenone ${ }^{16,19}$ and it was also shown that the catalyst activity of NHPI was enhanced in PEG $_{1000}$-DAIL than in traditional solvent. ${ }^{20}$ Then a series of substituted toluene derivatives was examined and the conversions were better than that in acetic acid. ${ }^{8,21}$ Generally, para- or ortho-substituted toluene (Run 3-4, 9-10 and 12-17) converted into the corresponding benzoic acid in excellent yields $(>85)$, no matter whether the substituents were electron-donating or electron-withdrawing. However, meta-substitution of the phenyl group decreased the degree of conversions dramatically. For example, $m$-xylene and mesitylene were oxidized to $m$-methylbenzoic acid and 3, 5dimethylbenzoic acid (Run 5-6) in $84.1 \%$ and $75.3 \%$ conversion, respectively. Also, $m$-amidotoluene and $m$ chlorotoluene afforded the product with lower conversions than their corresponding para-substituted toluene (Run 11 and 16). However, the selectivity was unaffected by the position of the substituent, it was affected by the kind of the substituent. It was found that toluene with electron-deficient substituent gave worse selectivity of acid than those with electron-rich ones, but the conversions were still high. For example, $p$-methoxytoluene, $p$ toluic acid and $o$-toluic acid were converted into their corresponding carboxylic acids in moderate selectivity as the substituent was electron-withdrawing (Run 12 to 14). And the oxidation of $p$-aminotoluene gave higher selectivity to corresponding acid than $p$-bromotoluene and $p$ chlorotoluene, although the conversions were all same (Run 9, 15 and 16). Meanwhile, trimethylbenzene and tetramethylbenzene underwent the reaction smoothly to afford the corresponding products with excellent conversion and selectivity (Run 6 and 7). In addition, the reaction of $p$-tert-butyltoluene occurred with some trouble, probably because of the steric hindrance resulting from the tert-butyl substituent, to give $p$-tert-butylbenzoic acid in $80 \%$ conversion with $96.9 \%$ selectivity (Run 8). $P$ Nitrotoluene having a strong electron-withdrawing substituent did not react under the present conditions (Run 19).

When the final reaction mixture was cooled to room temperature and ether was added, the upper layer of ether, containing product, was removed by decanta-

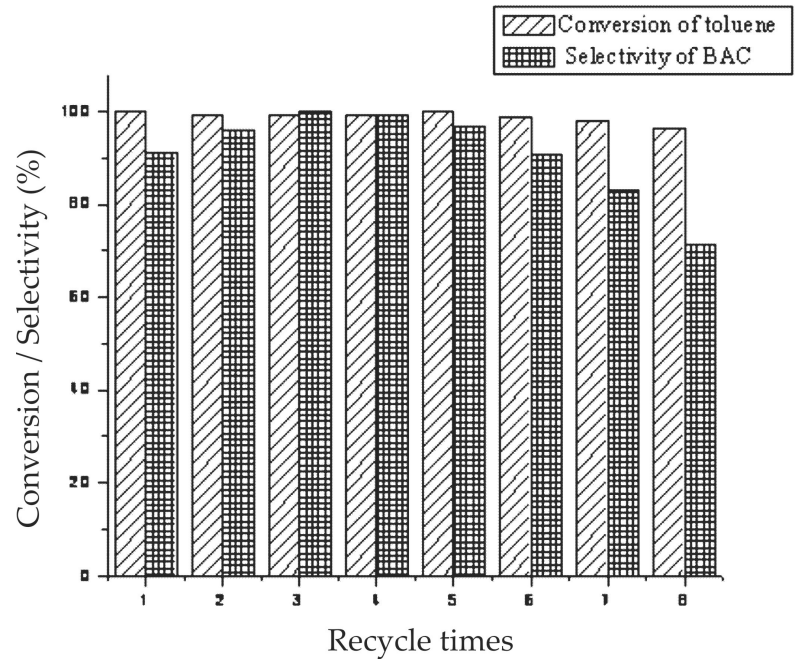

Figure 3. Repeating reaction using recovered $\mathrm{PEG}_{1000}-\mathrm{DAIL}$.

tion. Then only fresh substrate was recharged to the residual $\mathrm{PEG}_{1000}-\mathrm{DAIL}$ and the mixture was heated to react once again. The results from Figure 3 were shown that the procedure was repeated eight times with no appreciable decrease in conversions. The selectivity of toluene decreased obviously after 6 times because of the slight decomposition of NHPI. ${ }^{19}$

\section{CONCLUSION}

In summary, $\mathrm{PEG}_{1000}-\mathrm{DAIL}$ successfully replaced the traditional solvent acetic acid for NHPI catalyzed the oxidation of alkylaromatics to the corresponding acid by oxygen at normal pressure. The most useful catalyst mediator was $\mathrm{Co}(\mathrm{OAc})_{2}$ and several alkylaromatics were successfully oxidized to their corresponding acid under mild conditions. The $\mathrm{PEG}_{1000}-\mathrm{DAIL}$ has the advantages for enhanced the catalytic activity of NHPI, short reaction time, operational simplicity, and environmentally benign.

\section{REFERENCES}

1. L. Melone, C. Gambarotti, S. Prosperini, N. Pastori, F. Recupero, and C. Punta, Adv. Synth. Catal. 353 (2011) 147-154.

2. Q. Zhang, C. Chen, J. Xu, F. Wang, J. Gao, and C. Xia, Adv. Synth. Catal. 353 (2010) 226-230.

3. G. Yang, L. Zheng, G. Wu., X. Lin, and M. Song, Adv. Synth. Catal. 349 (2007) 2445-2448.

4. P. J. Figiel and J. M. Sobczak, New J. Chem. 31 (2007) 1668-1673.

5. M. Eikawa, S. Sakaguchi, and Y. Ishii, J. Org. Chem. 64 (1999) 4676-4679.

6. G. Zheng, C. Liu, Q. Wang, M. Wang, and G. Yang, Adv. Synth. Catal. 351 (2009) 2638-2642.

7. J. Jiang, Y. Jing, Y. Zhang, N. Zhang, J. Jiao, and W. Zhu, Catal. Lett. 141 (2011) 544-548.

8. Y. Yoshino, Y. Hayashi, T. Iwahama, S. Sakaguchi, and Y. Ishii, 
J. Org. Chem. 62 (1997) 6810-6813.

9. Y. Hu, Q. Ge, Y He, and M. Lu, ChemCatChem. 2 (2010) 392-396.

10. J. Wang, L. Liu, Y. F. Wang, Y. Zhang, W. Deng, and Q. X. Guo, Tetrahedron Lett. 46 (2005) 4647-4651.

11. Y. H. Liu, P. Cui, J. Sun, Y. Fan, and T. Jie, Chem. J. Chin. Univ. 27 (2006) 2314-2317.

12. I. Yavari and E. Karimi, Synth. Commun. 39 (2009) 1076-1083.

13. D. Fang, J. Yang, H. Zhang, and C. Jiao, J. Ind. Eng.Chem. 17 (2011) 386-388.

14. H. Zhi, C. Lu, Q. Zhang, and J. Luo, Chem. Commun. 2009 (2009) 2878-2879.

15. Y. Ishii, T. Iwahama, S. Sakaguchi, K. Nakayama, and Y.
Nishiyama, J. Org. Chem. 61 (1996) 4520-4526.

16. O. Fukuda, S. Sakaguchi, and Y. Ishii, Adv. Synth. Catal. 343 (2001) 809-815.

17. Y. Aoki, S. Sakaguchi, and Y. Ishii, Adv. Synth. Catal. 346 (2004) 199-202.

18. L. Zhou, Y. Chen, X. Yang, Y. Su, W. Zhang, and J. Xu, Catal. Lett. 125 (2008) 154-159.

19. G. Yang, Q. H. Zhang, H. Miao, X. Tong, and J. Xu, Org Lett. 7 (2005) 263-266.

20. X. Baucherel, L. Gonsalvi, I.W.C.E. Arends, S. Ellwood, and R. A. Sheldon, Adv. Synth. Catal. 346 (2004) 286-296.

21. N. Koshino, B.Saha, and J. S. Espenson, J. Org. Chem. 68 (2003) 9364-9370. 